\title{
Modeling and Exploitation Load Tests of the Suspended Route Slings Caused by Passage of the Locomotive at Various Speed along Mining Excavation
}

\author{
Kazimierz Drozd ${ }^{1 *}$, Aleksander Nieoczym ${ }^{1}$ \\ 1 Faculty of Mechanical Engineering, Lublin University of Technology, ul. Nadbystrzycka 36, Lublin, Poland \\ * Corresponding author's e-mail:k.drozd@pollub.pl
}

\begin{abstract}
Despite the fact that suspended monorails have been used in the mining industry for over 50 years it is necessary to continue research on the possibilities of increasing the unit mass of the transported load or the speed of people transport. The first step is to establish the exact dynamic load of suspended route' elements and compare this value with easy to calculation static load. The objective of the research was to determine the influence of speed and direction of travel on maximum load force applied to the sling of the route in mining excavation. The research results indicated that the speed of $2 \mathrm{~ms}^{-1}$ does not significantly influence the load on the sling. Theoretical hypothesis, stating that the estimation of the force value in the sling ought to be performed using projecting on a surface perpendicular to the route was confirmed. It was also proven that in order to characterize the geometry of the sling as well as a precise analysis of its load it is necessary to employ the length and the angle of the chain in relation to the above mentioned surface. Upon employing statistical analysis of the test results, the maximum dynamic effect of the locomotive passing was determined to be $20.1 \pm 2.5 \%$ of the value of the calculated static load for all slings, projected onto a plane perpendicular to the route. For a single sling, mounted on a test route section inclined at an angle of about $10^{\circ}$, the increase in force due to the passage of the locomotive was up to $21.0 \%$ of the static load for this sling.
\end{abstract}

Keywords: suspended monorail, dynamic force, mining auxiliary transportation.

\section{INTRODUCTION}

Suspended monorail is comprised of a set of elements configurated to operate in various transport systems. Thanks to numerous advantages (e.g. possibility of transporting loads on branched railroads, module structure construction allowing to adjust its configuration to the transported loads, low sensitivity to excavation traffic) [1], overhead railroads, manufactured by several companies [2-3] are used for horizontal transport of goods and people in underground mine workings. Gravity force coming from the transport trolleys with the load causes normal and tangential stresses in the rail material. Bending stresses, however, are most crucial $[4,5]$. The force from the load is transferred to the excavation support (arc or anchor) through a chain sling.
The limit of the weight of the carriages along with the load, which can be on two adjacent rails at the same time, results from the load capacity of the chain sling placed between these rails. The maximum load capacity of the chain is specified in the standard [6-8] and must not exceed $50 \mathrm{kN}$. Simultaneous fulfilment of the conditions of the maximum load of the rail and the sling is achievable by adjusting the distance between the loaded carriages, as well as possibly changing the rail length.

Identification of real force values in chain slings on the route located in a mining excavation was performed for two movement modes: drive $[4,9]$ and braking [9]. In both publications, the courses of forces, recorded for single chain slings and in $\mathrm{V}$-shaped slings in a time frame were presented. In publication [9] it was proved that the change in the running speed within the range (1.0, 
$1.1,2.0) \mathrm{ms}^{-1}$ did not change in the forces generated in the slings, while they depended on the length of the rails.

The maximum values of the forces recorded during braking from an initial speed of $1.0 \mathrm{~ms}^{-1}$ were identical for all slings, but their geometric characteristics were not given. The emergency braking test from the same initial speed showed the occurrence of forces with values approximately $20 \%$ higher compared to the forces during constant speed. The overload generated under emergency braking conditions reached a value of $3 \cdot g$.

A practical conclusion from the study [9] is to combine the increase of speed and the changes to the construction of railways for people transport, which would protect the operator and the people transported from the overloads occurring during braking. In the study [4], however, an extended mathematical model was proposed to calculate the forces considering the angle of the sling. Apart from the measurement results of force in the slings, mathematical analyses for the loading conditions of the rail and the slings were provided as a function of the number of trolleys loading the rail and the distance between the trolleys. Strength conditions of the running rail were also researched in terms of its strength, wear and buckling.

Analysis of the changes to the force in chain slings of the drive route is also considered on the basis of vibrations in the drive system. In [10] a mathematical model of the vibrations of the wheels of a drive bogie, which allows one to determine the dependency between the geometrical parameters of construction elements of the bogie and the character of the occurring vibrations. Vibration frequencies of the drive route as well as its maximum angular and linear deflection. These analyses were further developed into another mathematical model of the movement of suspended route in a form of elastic bodies linked together [11]. An amplitude of variation of coordinates of the position of the centres of the driving carriage wheels and the velocity components were determined. The influence of the elastic-dissipative joints on the movement parameters during braking. Calculation results indicated that longitudinal dynamic forces acting on the route may exceed the value of the braking force over 1.6 times.

Increasing the speed directly influences an increase in dynamic load occurring during braking. These forces are transferred through slings to arch supports of the excavation, which may cause buckling of the arc support and damage to the anchor bolt, which fixes the arc support to the excavation $[12,13]$. Limit speed values of the transport system were determined, as well as corresponding forces transferred to anchor bolts at which the bolts are damaged. It was therefore proven that the calculations (numerical calculations included) aiming to analyse critical load and buckling of the bending arc support during the braking process of the transporting system ought to be the first step in the process allowing for increasing the speed of suspended monorails [1315]. Similar conclusions were drawn in the study [1], where the lab research results of emergency braking of the recorded values of the braking force were used as input data to perform computer simulations of the dynamic loading of elements of the suspended monorail route. Model tests showed an equal value of the braking force from initial velocities in the range $v=(3.6-5.7) \mathrm{ms}^{-1}$. It was shown that the force occurring during braking causes a significant increase in the load on the route rail, while it has affects less significantly the load on the excavation lining doors.

The total mass, load on selected bogies and the distance between the bogies are the basic variables for configurating the suspended monorail system. These variables are the input data for the software supporting the configuration of the transport system. A disadvantage of those programmes is a lack of a calculation module allowing one to determine the values of force in the slings. The programmes described in the studies $[1,16]$ allow one to perform traction calculations with the following data presented: the pulling force of the driving and braking bogies, the coefficient of friction (between the driving wheels and the rail) and the dynamic braking coefficient. A separate group of computer-aided calculation programs are programs enabling the analysis of the effect of travel speed and inertia forces during emergency braking on the safety of the transported people, described in publications $[17,18]$. Such programmes also allow for a simulation of swaying of the carriages of a passenger train during its movement.

The authors' research program differs significantly from the ones presented in literature as well as it exceeds the ones to be currently found in literature. Instead of computer or laboratory simulations, which are reported in the literature, the authors conducted tests on a real object under typical operating conditions. For that reason, a complete overhead tractor with its own internal 
combustion drive was used, while usually the dynamics of a single bogie, possibly hydraulically driven from an external source, is studied. The set used for the tests weighed nearly $4880 \mathrm{~kg}$, and the highest force on a single bogie was $14.7 \mathrm{kN}$, while typical tests are performed with a bogie of a weight not exceeding $5.0 \mathrm{kN}$. Elements of the overhead rail route were equipped in force sensors mounted on a section more than twice the length of the tractor used for the tests. The measuring section was characterized by a fairly steep incline (c.a. $10^{\circ}$ ) and the tests were performed for both directions of travel. As a result of the measurements taken according to the assumed program, it was possible to use the appropriate mathematical apparatus to validate and further interpret the results of the presented tests.

As a result of the studies on dynamic loading of the actual route presented in this paper it is assumed that the safety factor values of the suspension elements of the suspended monorail route can be reduced. Alternatively, a threat to transportation safety due to the expected increase in the speed of the suspended queue route, currently limited to $2 \mathrm{~ms}^{-1}$, can be excluded [17]. Both of these effects are associated with measurable economic benefits due to material savings, increased freight transportation efficiency, and increased effective working time for the staff.

\section{METHODS AND EXPERIMENTAL}

\section{Mathematical model of a route of a suspended monorail}

The following assumptions and observations were utilized to mathematically describe the loading process of a single-leg sling mounted on a suspended railroad by trolleys (Figure 1):

- the rails of the suspended railroad were inclined at the angle of $\Delta$ with respect to the horizontal direction,

- both rails adjacent to the considered sling have the same length $L$,

- the rail joint ought not to be located directly under the excavation support, so the sling chain attached to this joint (and the force $F_{G}$ that is generated in this chain) may have a direction deviated from the plane normal to the direction of the route by the angle of the sling marked $\alpha$,

- the convention for the sign of the angle $\alpha$ is measured from a plane perpendicular to the rail in the direction of elevation it is positive, as it is for all slings shown in Figure 1,

- the distance between the bogies of the suspended rail is a sequence of $L_{1}$ and $L_{2}$ dimensions,

- the source of load on the rail is the component of gravity force per one bogie (e.g. $\mathrm{w}_{2}$ ) with value $F_{G} \cdot \cos \Delta$,

- the gravity force component of the trolley can be distributed half on each pair of wheels, $L_{3}$ apart, rolling on both sides of the rail web (as shown for trolley $\mathrm{w}_{3}$ ), but this distance is neglected in further considerations,

- the gravity force component $F \cdot \cos \alpha$ must be balanced by normal to the rail component of the force acting in the sling with the value $F_{G} \cdot \cos \alpha$, therefore - in order to eliminate the effect of the sling angle on its load - the load on the route should be considered in the plane (arch of the excavation shell) perpendicular to the direction of the rails,

- the force $F_{G}$ generated in the sling causes the longitudinal component of $F_{G} \cdot \sin \alpha$ to act on the rail joint,

- the rolling friction force, acting between the steel wheels of the trolley and the lower flange of the steel rail, is insignificant due to the small value of the friction coefficient,

- the only forces which can cause longitudinal contact between the trolley and the rail is the driving force $F_{N}$ or the braking force $F_{h}$,

- if the component $F_{G} \cdot \sin \alpha$, acting on the rail joint, does not balance the driving force $F_{N}$ or braking force $F_{h}$, then force $\overrightarrow{F_{w}}=\overrightarrow{F_{G} \cdot \sin \alpha}+\left(\overrightarrow{F_{N}} \cup \overrightarrow{F_{h}}\right)$ occurs, which causes displacement of the route (rotation of the joint in relation to the point of attachment of the sling $\mathrm{D}$ to the excavation lining) to a new equilibrium position (Figure 1),

- if all the considered bogies on the rails connected to the sling have the same mass $m_{a}$ then the force $F_{G}$ generated in this sling can be calculated using formula (1),

- should $L_{1}$ dimension be greater than the length of the rail $L$ and all the bogies, which are on the rails connected to the sling under consideration, had the same mass $m_{a}$, then the force $F_{G}$ occurring in this sling can be calculated from formula (2).

$$
\begin{aligned}
F_{G}= & \frac{m_{a} \cdot g}{1000 \cdot L} \cdot \frac{\cos (\Delta)}{\cos (\alpha)} \cdot\left[L+\left(L-L_{1}\right)+\right. \\
& \left.+\left(L-L_{2}\right)+\left(n_{2}-3\right) \cdot\left(L-L_{1}-L_{2}\right)\right] \leq Q
\end{aligned}
$$




$$
\begin{gathered}
F_{G}=\frac{m_{a} \cdot \mathrm{g}}{1000 \cdot L} \cdot \cos \Delta \cdot \\
\cdot \sec \alpha \cdot\left[L+\left(L-L_{2}\right)\right] \leq Q
\end{gathered}
$$

where: $F_{G}$ - force generated in the sling $[\mathrm{kN}]$, $\mathrm{g}$ - gravitational acceleration $\left[\mathrm{ms}^{-2}\right]$, $L-$ length of the rail $[\mathrm{mm}], \Delta-$ slope angle $\left[{ }^{\circ}\right], \alpha-$ sling angle measured in relation to the plane perpendicular to the rail $\left[^{\circ}\right], L_{1}$ - distance between the centres of the carriages in the same unit [mm], $L_{2}$ - distance between the entres of the trolleys in different units [mm], $Q$ - permissible sling load determined for the assumed safety factor $[\mathrm{kN}]$, $n_{2}$ - number of trolleys, closest to the heaviest trolley, located at the same time on two rails of railroad route connected to considered sling [-].

The highest static load of the sling was determined for such a position of the set when the heaviest bogie of the set with mass $m_{a(\max )}$ was exactly in the place of fixing this sling to the rail joint. The value of this load with the force $F_{G}$, separately for each sling, was calculated from the following formula (3):

$$
\begin{aligned}
& F_{G}=\frac{g \cdot \cos (\Delta)}{1000} \cdot\left\{m_{a(\max )}+\right. \\
&\left.+\sum_{i=1}^{n_{2}-2}\left[\frac{m_{a(i)}}{\cos \left(\alpha_{(i)}\right)} \cdot\left(1-\frac{L_{2(i)}}{L}\right)\right]\right\}
\end{aligned}
$$

where: $m_{a(\max )}-$ mass of that trolley which has the highest mass in the whole set $[\mathrm{kg}]$, $j-$ iteration variable $[-]$.

\section{Characterization of experimental methods}

The research was carried out along the route of the suspended monorail that is located in the haulage tunnel in the area of shaft VI of the Budryk Mine. The excavation was $270 \mathrm{~m}$ long and was equipped with a flexible arch support made from the V36 profile with a spacing of $0.75 \mathrm{~m}$. The pit inclination angle equalled $\Delta=\left(6^{\circ}-12^{\circ}\right)$, and in the measuring section of the route it was $\Delta=10 \pm 2^{\circ}$. For the time of the survey, it was possible to completely disconnect the route from the network of the other routes of the suspended monorail in the mine.

The measured route with the length of 13.5 $\mathrm{m}$ was equipped with actuators marked A-H and mounted on Z1-Z8 slings (Figure 2). Strain gauges type $\mathrm{FC}$ [19] with a measurement range of $100 \mathrm{kN}$ and sampling of $10 \mathrm{~Hz}$ were applied. All slings mounted on the test section were characterized by a nominal load capacity of up to $Q=$ $50 \mathrm{kN}$, while maintaining the safety factor $n=4$ related to the breaking load [20]. On the measured route there was not existed stabilizing slings.

Table 1 presents the characteristics of the slings in the unloaded state and the corresponding force sensors located along the measured route section. The length of the slings ranged from 1040 $\mathrm{mm}$ to $1230 \mathrm{~mm}$. They were characterized by an $\alpha$ angle of not less than $9.6^{\circ}$ and a maximum of $15.3^{\circ}$. In Table 1 , two pairs with similar values of the following parameters were listed: the angle $\alpha$, the length of the rails $(L=2250 \mathrm{~mm})$ mounted on both sides of the sling, and the length of the sling chain $L_{z}$. As a result of the aforementioned

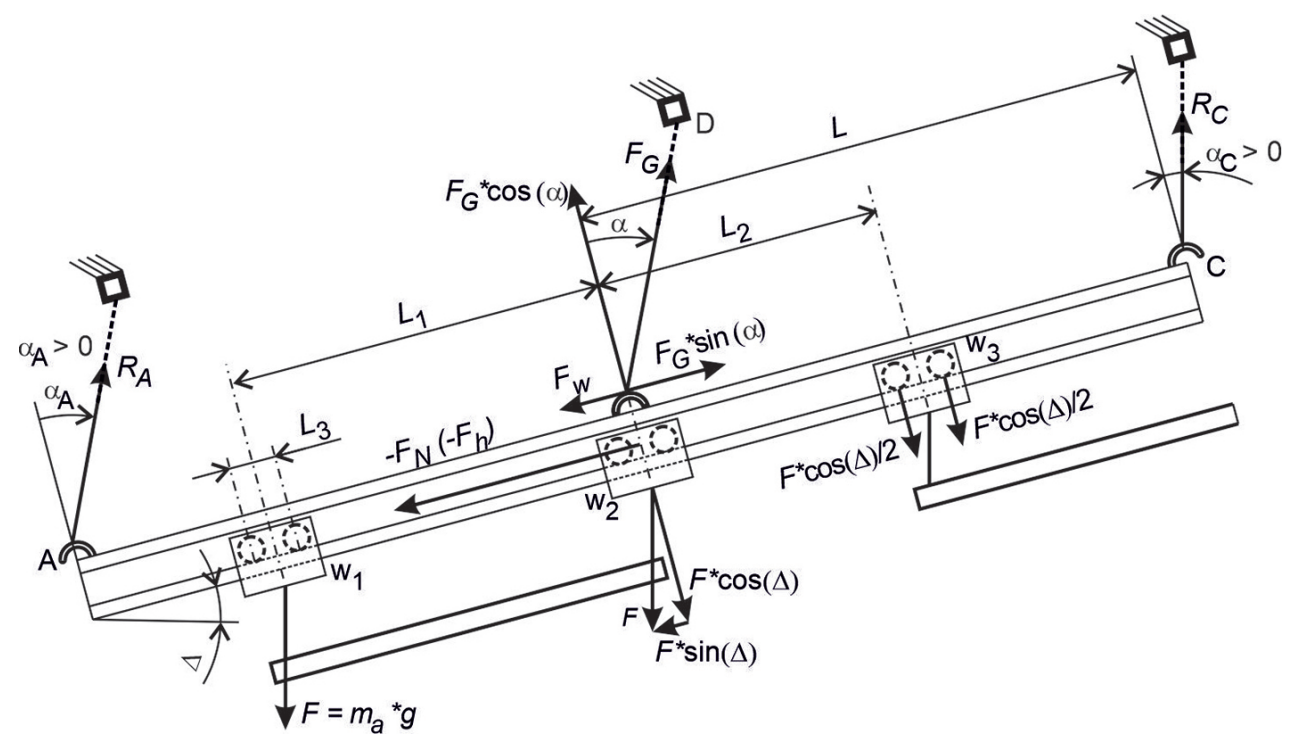

Fig. 1. Scheme of the process of loading a single-leg sling by three trolleys on route rails attached to the sling 


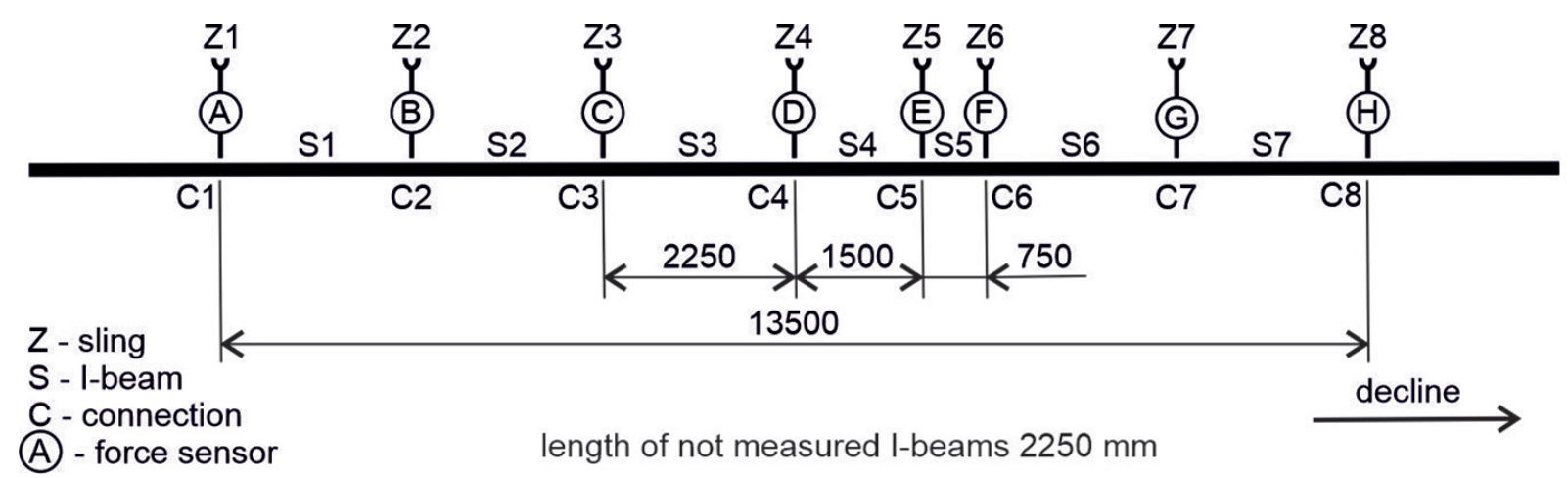

Fig. 2. Scheme of the route in the excavation where measurements were taken

Table 1. Geometrical characteristics of the slings on the measured route section

\begin{tabular}{|c|c|c|c|c|c|c|}
\hline \multicolumn{2}{|c|}{ Designation } & \multirow{2}{*}{$\begin{array}{l}\text { Sling length } L_{z} \\
\mathrm{~mm}\end{array}$} & \multicolumn{2}{|c|}{ Angle of the sling for the travel, ${ }^{\circ}$} & \multirow{2}{*}{$\begin{array}{l}\text { Rail length } L, \\
\mathrm{~mm}\end{array}$} & \multirow{2}{*}{$\begin{array}{l}\text { Pair of slings } \\
\text { for comparison }\end{array}$} \\
\hline Of the sling & $\begin{array}{l}\text { Of the force } \\
\text { sensor }\end{array}$ & & Unloaded & $\begin{array}{l}\text { Displaced by } \\
30 \mathrm{~mm}\end{array}$ & & \\
\hline \multirow[b]{2}{*}{ Z1 } & \multirow[b]{2}{*}{ A } & \multirow[b]{2}{*}{1230} & \multirow[b]{2}{*}{9.6} & \multirow[b]{2}{*}{11.0} & \multirow[t]{2}{*}{2250} & \\
\hline & & & & & & \\
\hline $\mathrm{Z2}$ & B & 1190 & 13.3 & 14.8 & \multirow{2}{*}{2250} & 1 \\
\hline Z3 & C & 1060 & 11.8 & 13.5 & & 2 \\
\hline Z4 & $D$ & 1040 & 14.2 & 15.9 & 2250 & \\
\hline Z5 & $E$ & 1050 & 15.3 & 17.0 & 1500 & \\
\hline \multirow{2}{*}{ Z6 } & \multirow[b]{2}{*}{$\mathrm{F}$} & \multirow{2}{*}{1120} & \multirow{2}{*}{11.0} & \multirow[b]{2}{*}{12.6} & 750 & \\
\hline & & & & & 2250 & \\
\hline $\mathrm{Z7}$ & G & 1050 & 11.8 & 13.5 & 2250 & 2 \\
\hline Z8 & $\mathrm{H}$ & 1100 & 13.4 & 15.0 & 2200 & 1 \\
\hline & & & & & 2250 & \\
\hline
\end{tabular}

analogies, comparable force measurement results were expected for the indicated pairs, which was used as a test for repeatability of the tests conducted. Simulations of the angle change for the sling $\alpha$, assuming an increasing sling rotation angle - with respect to the point of its attachment to the support arc - as a result of the route displacement by $30 \mathrm{~mm}$ [15], showed an increase of this angle by $1.7^{\circ}$. Such an angle change occurred for slings with a small length $L_{Z}$ but attached at a large angle $\alpha$ (Z4, Z5 and Z8). Taking into account that according to formulas (1) and (2) the sling load depends on the function $\sec \alpha$, the predicted change in the value of $\alpha$ angle as a result of the route loading can lead to an increase in the sling load $L_{G}$ by up to $0.9 \%$ (for sling Z5).

The tests were conducted during the drive of a diesel overhead tractor type DLZ110F-II (Figure 3) with a nominal power of $81 \mathrm{~kW}$ and a maximum pulling force equal $80 \mathrm{kN} \mathrm{[21].} \mathrm{The} \mathrm{charac-}$ teristics of the individual system comprising the locomotive employed in the study are presented in Table 2. The locomotive contained four drivebrake bogies, two of which (w4 and w5) were separate systems. The other two drive-brake bogies were also the bogies carrying the locomotive engine assembly, which was the heaviest in the entire set. It was assumed that each of the bogies of the engine set $\left(\mathrm{w}_{2}\right.$ and $\left.\mathrm{w}_{3}\right)$ transferred the force of gravity of half the mass of this set, i.e. $14.7 \mathrm{kN}$. Due to the fact that the cab weight was much less significant, each cab was assumed to load one bogie. The total weight of the locomotive including the operator equalled $4880 \mathrm{~kg}$.

Measurements of the forces in the slings of the suspended monorail route were taken during travels on incline and decline at a constant speed of $v=(0.5,1.0,2.0) \mathrm{ms}^{-1}$. Before each back and forth travel of the locomotive through the measured section, the force sensor readings were zeroed. The length of the locomotive, measured between the centres of the bogies $(6.25 \mathrm{~m})$, was 


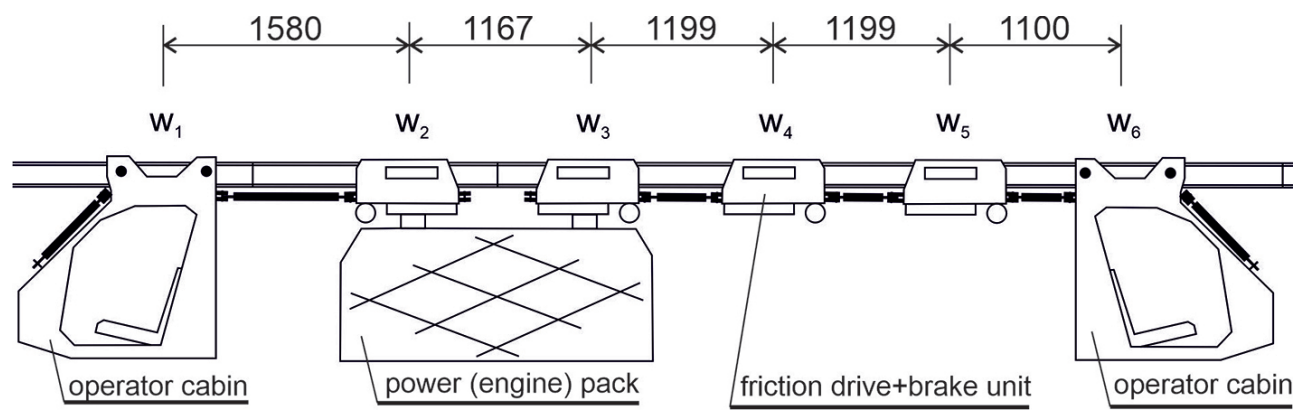

Fig. 3. Scheme of the DLZ110F-II type suspended locomotive with traction used for testing and markings assigned to each bogie

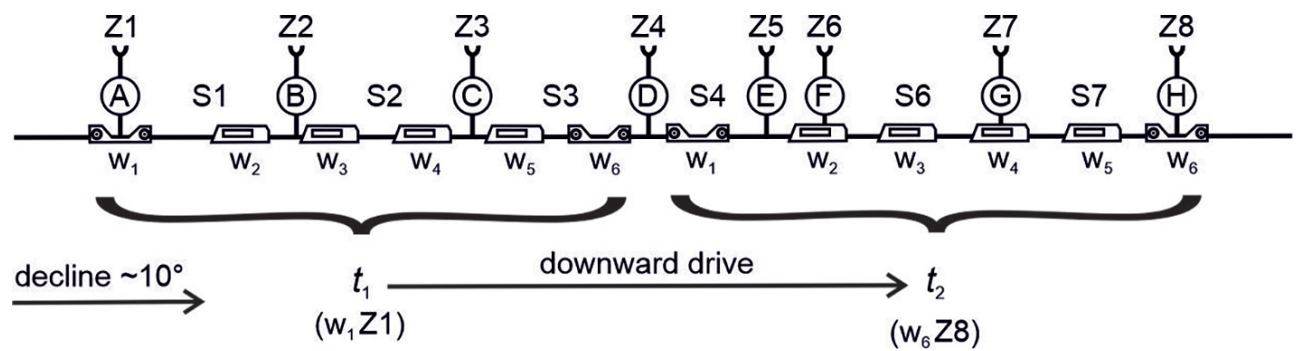

Fig. 4. End locations of each boogie between moments $t_{1}$ and $t_{2}$, when the entire locomotive was located on the measured section of the route while on decline

more than twice the distance of $13.5 \mathrm{~m}$ between the measured side slings Z1 and Z8 (Figure 2), on which the force sensors $\mathrm{A}$ and $\mathrm{H}$ were located. Due to the fact, there was able to study the dynamic effects generated by the movement of the suspended monorail during the time (from $t_{1}$ to $t_{2}$ in Figure 4), when the entire locomotive (all bogies) was on the measuring section (Figure 4).

Analyses of the influence of the travel of the locomotive along the measured section on the dynamic load effects were performed for three types of data. The first set was a sum of force projections measured on a plane perpendicular to the direction of the route when the whole locomotive was on the measuring section $\left(\mathrm{w}_{1} \mathrm{Z1}-\mathrm{w}_{6} \mathrm{Z} 8\right)$. Static calculations indicate that the sum of force projections in the slings in this case should be $47.2 \mathrm{kN}$. The sequence of passing individual slings and load sensors by successive bogies of the locomotive was presented in Table 3. This table ought to be read in columns starting from the left side during the downward travel, and for the upward

Table 2. Assemblies comprising the DLZ110F-II self-propelled suspension locomotive

\begin{tabular}{|l|c|c|c|c|}
\hline \multicolumn{1}{|c|}{ Name } & Bogie designation & Own mass, $\mathrm{kg}$ & Number of elements & Weight summed up, kg \\
\hline Operator cabin & $\mathrm{w}_{1} \mathrm{w}_{6}$ & 500 & 2 & 1000 \\
\hline Power (engine) pack & $\mathrm{w}_{2} \mathrm{w}_{3}$ & 3000 & 1 & 3000 \\
\hline Friction drive unit & $\mathrm{w}_{4} \mathrm{w}_{5}$ & 395 & 2 & 790 \\
\hline Operator & & & & 90 \\
\hline Total & $\mathrm{w}_{1}-\mathrm{w}_{6}$ & & & 4880 \\
\hline
\end{tabular}

Table 3. Order of passing slings by bogies when the whole locomotive is on the measuring section

\begin{tabular}{|l|l|l|l|l|l|l|l|l|l|l|l|l|l|l|l|l|l|l|l|l|l|l|l|l|}
\hline \multicolumn{11}{|c|}{ Sogie number $\mathrm{w}_{\mathrm{x}}$} \\
\hline 1 & 6 & 4 & 2 & 5 & 3 & 6 & 1 & 6 & 4 & 2 & 5 & 5 & 3 & 4 & 1 & 6 & 4 & 2 & 3 & 5 & 3 & 2 & 1 & 6 \\
\hline \multicolumn{10}{|c|}{ number $\mathrm{ZY}$} \\
\hline 1 & 4 & 3 & 2 & 4 & 3 & 5 & 2 & 6 & 4 & 3 & 5 & 6 & 4 & 5 & 3 & 7 & 6 & 4 & 5 & 7 & 6 & 5 & 4 & 8 \\
\hline
\end{tabular}


travel analysis - in columns from the right. When one of the heaviest bogies $\left(\mathrm{w}_{2}\right.$ or $\left.\mathrm{w}_{3}\right)$ passes the sling - the designation of the load sensor on this sling is also presented. For example, during the downward travel the carriage $\mathrm{w}_{2}$ passes the sling $\mathrm{Z} 2$ (the third column from the left) along with the force sensor $B$, then the carriage $\mathrm{w}_{5}$ passes the sling Z4 (the fourth column), and next the carriage $\mathrm{w}_{3}$ passes the sling $\mathrm{Z} 3$, where force sensor $\mathrm{C}$ was installed.

The second data set concerned the sum of the projections, of the forces measured in the slings on a plane perpendicular to the route at the moment when $=$ the heaviest locomotive bogies were located on the measured section. This set was described by the end positions $\mathrm{w}_{3} \mathrm{Z} 1$ and $\mathrm{w}_{2} \mathrm{Z} 8$.

The third data set consisted of the values of force directly measured by each sensor during the travel of the locomotive through the route measurement section. The maximum values measured while passing in both directions at different speeds were compared. The homogeneity of the distributions of the force values measured by sensors, B and H, and separately, C and G (pairs listed in Table 1), for a single run were also analysed.

In order to assess the accuracy and repeatability of the measurements, from 3 to 5 cycles of the travels were performed and the results were subjected to statistical tests for the assumed significance level of $\alpha=0.05$. The runs of the sum of force projections on the plane normal to the route, for the range of $\mathrm{w}_{1} \mathrm{Z1}-\mathrm{w}_{6} \mathrm{Z} 8$, determined for different run speeds were tested for homogeneity. This test was conducted in two stages for 15 pairs of results. In the first stage, a Bartlett test, which is used as a test preceding the test for homogeneity of means, was used. Homogeneity of variance in the study populations (differing in speed and direction of travel) was used as hypothesis $\mathrm{H}_{0}$. Despite the fact that the condition for this test is required for normality of distribution, it was omitted due to the significant sample sizes ranging from 40 to 160 . For the second stage Student's t test, for the same range of locomotive positions between $\mathrm{w}_{1} \mathrm{Z} 1$ and $\mathrm{w}_{6} \mathrm{Z} 8$. Hypothesis $\mathrm{H}_{0}$ was as follows: the mean values measured for the different groups are similar to each other. Testing of this hypothesis was done in pairs and with the results of Bartlett test indicating the equality (or lack thereof) of the variance for each pair of results. The same two tests were used to test for differences between force waveforms over time for each of the force sensor pairs described in Table 1.
Moreover, two non-parametric statistical tests were performed for the range of bogie positions $\mathrm{w}_{3} \mathrm{Z1}-\mathrm{w}_{2} \mathrm{Z} 8$, i.e., when the heaviest bogies were on the measurement section of the route. The first was the Kruskal-Wallis test to assess the differences in the distributions of the variable for all six speed and direction cases tested. The $\mathrm{H}_{0}$ hypothesis that the populations have the same distributions (distributions) was tested. In order to compare the study groups in pairs, the recommended Mann-Whitney test for assessing differences in means was not performed because a more important parameter than the mean in this case was the distribution of the distributions. For this reason, using the non-parametric Smirnov test, the correctness of the hypothesis $\mathrm{H}_{0}$ assuming equality of the distributants in the compared groups was tested.

\section{MEASUREMENT RESULTS}

Figure 5 shows the results of force measurements on slings A-H during the tractor travel on the incline and decline at a speed of $0.5 \mathrm{~ms}^{-1}$. The maximum values recorded by the force sensors during both runs were comparable and equalled about $25 \mathrm{kN}$ for slings $\mathrm{Z} 1 \div \mathrm{Z3}$ (force sensors $\mathrm{A} \div \mathrm{C}), \mathrm{Z7}(\mathrm{G})$, and $\mathrm{Z8}(\mathrm{H})$.

Figure 5-7 also presents the waveform $\Sigma$. The force values in this case represent the sum of the force projections, taken by the individual sensors on a plane perpendicular to the direction of the route. The time range of this waveform corresponds to such a position of the locomotive on the route when the heaviest bogies, $\mathrm{w}_{2}$ and $\mathrm{w}_{3}$, were located on the measuring section between slings $\mathrm{Z} 1$ and $\mathrm{Z} 8$. The side positions of these bogies are $\mathrm{w}_{2} \mathrm{Z} 1$ and $\mathrm{w}_{3} \mathrm{Z} 8$. The part of the course marked with a blue rectangle corresponds to the position of the locomotive when all bogies were on the measuring section (Figure 4). End positions of these bogies are marked $\mathrm{w}_{1} \mathrm{Z} 1$ and $\mathrm{w}_{6} \mathrm{Z} 8$. Due to the fact that the measured data for this part of the diagrams (Figs. 5-7) had a normal distribution, its parameters were marked according to the formula $\mathrm{N}(\mu, \sigma)$ and the values of the minimum and maximum force for this rectangle were presented.

Increasing the locomotive travel speed to $1.0 \mathrm{~ms}^{-1}$ (Figure 6) did not significantly change the parameters during travel in both directions. Upon analysing the force waveforms, it is noted that in sling Z2, with sensor B, the maximum 

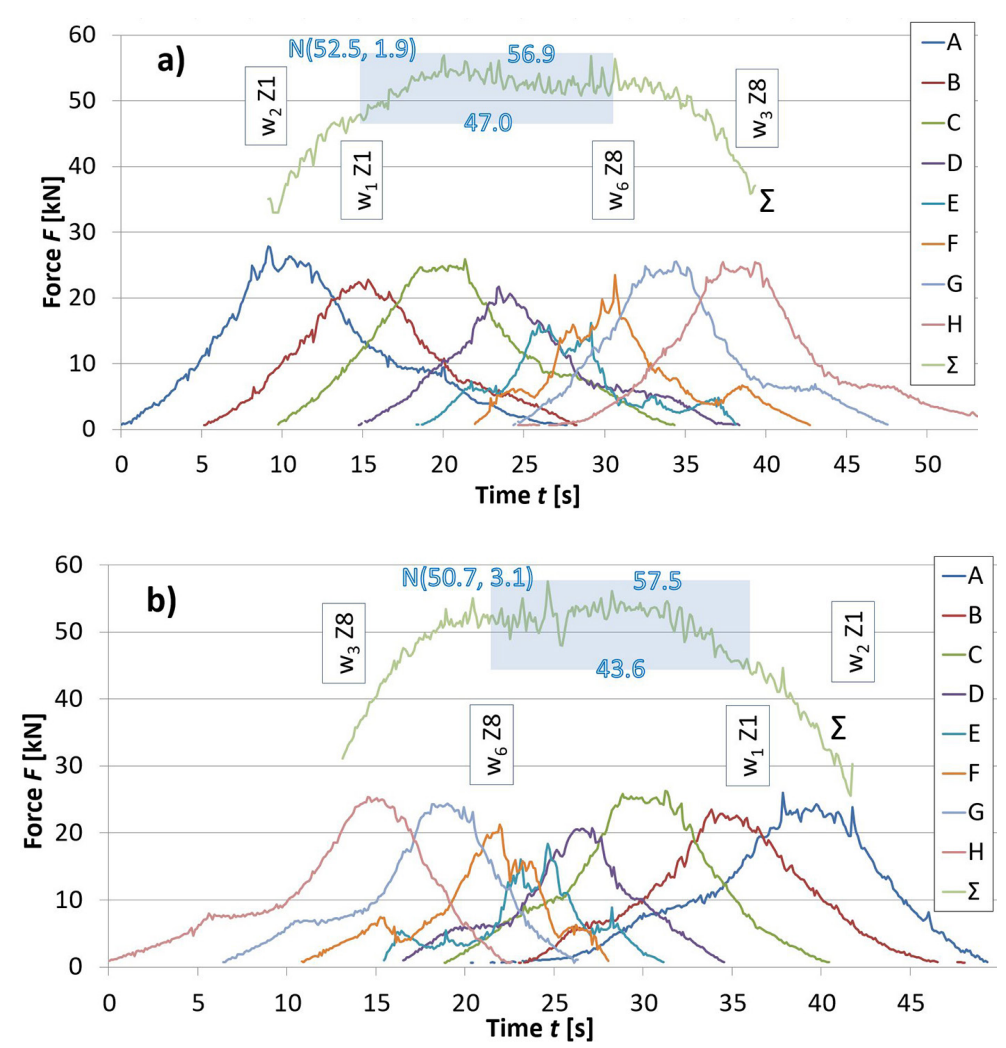

Fig. 5. The progression of changes of forces recorded by individual sensors and the sum of projections onto a plane perpendicular to the direction of the route, during the passage of the locomotive at a speed of $0.5 \mathrm{~ms}^{-1}: \mathrm{a}-$ on the decline, $\mathrm{b}-$ on the incline
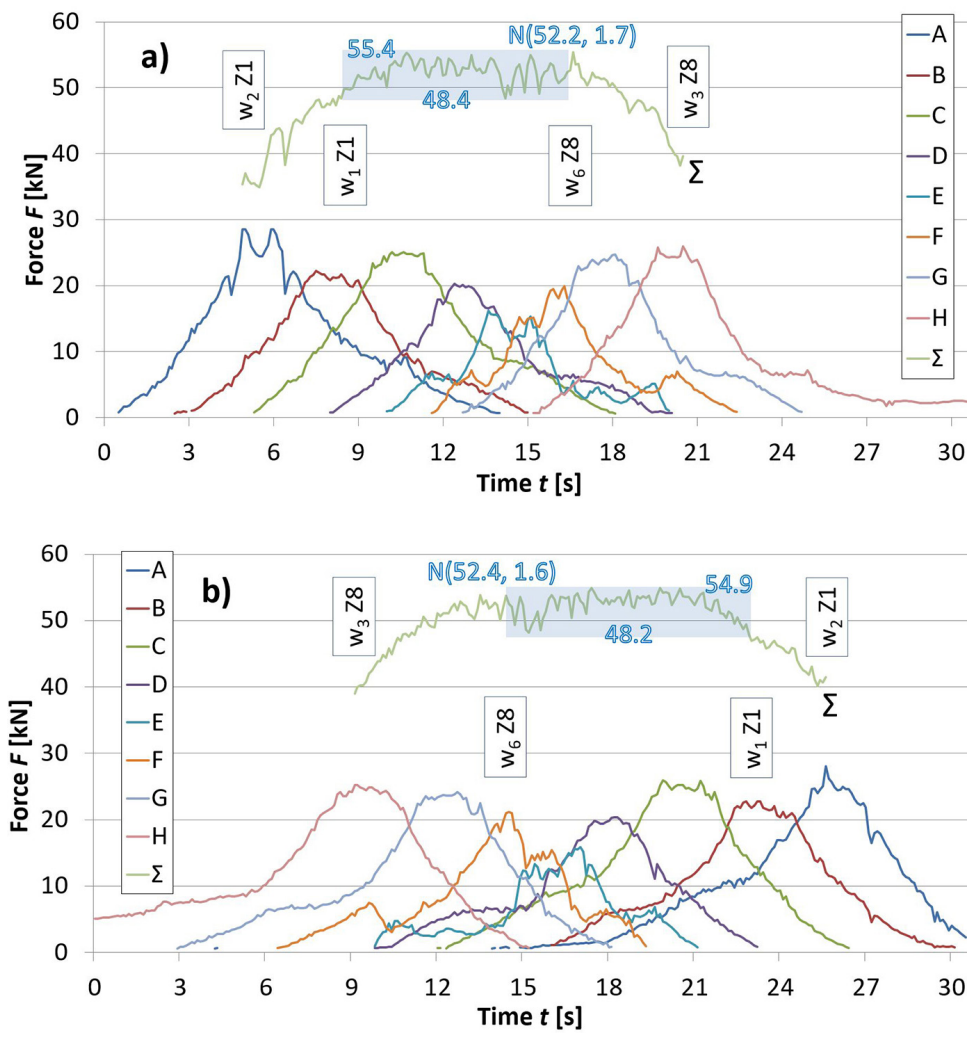

Fig. 6. Progression of changes to the forces recorded by selected sensors and the sum of projections onto a plane perpendicular to the direction of the route, during the passage of the locomotive at a speed of $1.0 \mathrm{~ms}^{-1}: \mathrm{a}-$ on the decline, $\mathrm{b}-$ on the incline 

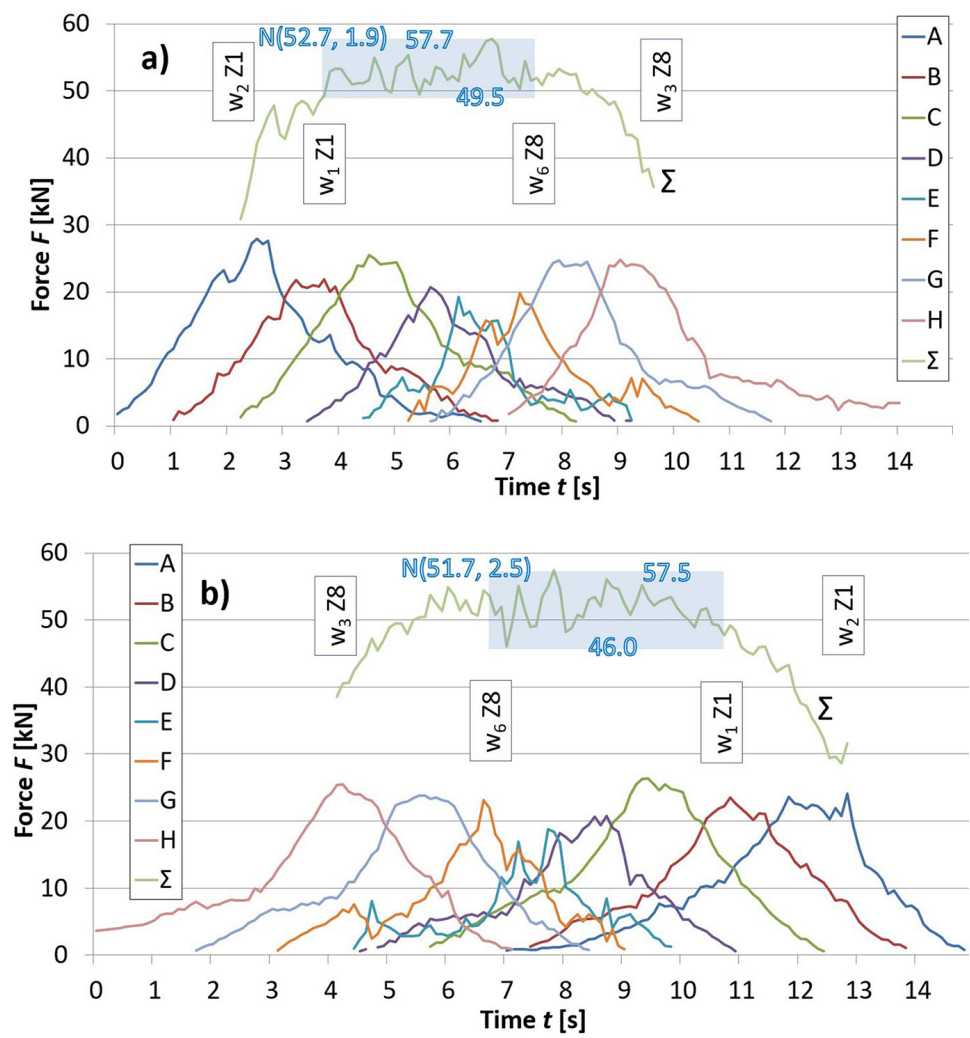

Fig. 7. Progression of changes to the forces recorded by selected sensors and the sum of projections onto a plane perpendicular to the direction of the route, during the passage of the locomotive at a speed of $2.0 \mathrm{~ms}^{-1}: \mathrm{a}-$ on the decline, $\mathrm{b}-$ on the incline

force was less than that recorded in sensor A. For another sling $\mathrm{Z} 3$, in sensor $\mathrm{C}$, the maximum recorded force was the average of the readings from sensors A (sling Z1) and B (Z2). Therefore increasing the force value in one sling caused a comparable decrease in the response value of the neighbouring sling.

During the locomotive travel at $2.0 \mathrm{~ms}^{-1}$ on decline (Figure 7a), changes to the force values in sensors $\mathrm{A}, \mathrm{B}$, and $\mathrm{C}$ are similar in terms of pattern to those recorded at $1.0 \mathrm{~ms}^{-1}$ (Figure $6 a)$. The maximum force values recorded by sensors $\mathrm{B}, \mathrm{D}, \mathrm{E}$, and $\mathrm{F}$ (slings Z2, Z4, Z5, and Z6) were comparable. The highest force, of almost 28 $\mathrm{kN}$, was recorded for the first sling on measurement route $\mathrm{Z1}$, with sensor $\mathrm{A}$. When the tractor travelled at $2.0 \mathrm{~ms}^{-1}$ on an incline (Figure $7 \mathrm{~b}$ ), except for force sensors $\mathrm{D}$ and $\mathrm{E}$, the maximum values recorded by the other sensors were comparable. There was an "averaging of response" in the slings during the upward travel. The highest value was found in sensor $\mathrm{C}$ for sling $\mathrm{Z} 3$ and was approximately $26 \mathrm{kN}$.

For each travel of the train, except for the ascending run at $0.5 \mathrm{~ms}^{-1}$ (Figure $5 \mathrm{~b}$ ) and $2.0 \mathrm{~ms}^{-1}$ (Figure $7 b$ ), the highest maximum forces were recorded in sling Z1 with force sensor A. This phenomenon can be explained by the fact that the sling located higher on the route was mounted at an angle $\alpha<\Delta$, which was smaller than the angle of sling Z1. A similar dependency was observed for sling Z2 with sensor B. However, in this case the sling angle was comparable with the slope angle $\Delta$ and, additionally, a correlation was observed between the increase in force in one sling and its simultaneous decrease in the adjacent sling.

\section{ANALYSIS OF THE MEASUREMENT RESULTS}

\section{The entire train is located on the measuring section $w_{1} Z 1-w_{6} Z 8$}

The values of the forces recorded by the sensors were calculated for the direction perpendicular to the rail, i.e., the direction of rail reaction to the gravity forces of the bogies, and summed up. For example, for a downhill travel at a speed of $2.0 \mathrm{~ms}^{-1}$, the highest value of this sum $(57.7 \mathrm{kN}$ as seen in Figure 7a) was observed at the moment when both of the heaviest bogies of the motor unit 
marked $\mathrm{w}_{2}$ and $\mathrm{w}_{3}$ were located on rails adjacent to the sling Z3 or Z5 (Figure 2, Table 3). The occurrence of a high value of the load force on the sling $\mathrm{Z} 3$ with the force sensor $\mathrm{C}$ can be explained by the fact that the longest rails influence of the mass of the bogies located on them. For the same reason, it would be expected that the values of forces loading the sling Z7 with the force sensor $\mathrm{G}$ would be similar. The occurrence of the highest sum of forces in sling Z5, with force sensor E, could be related to the high rate of force build up, due to the fact that it was connected to short rails $(750 \mathrm{~mm}$ and 1500 $\mathrm{mm}$ ), and at the same time it could carry a higher longitudinal load, since the sling angle $\alpha$ was the highest here along the whole route (Table 1).

During the decline run at $0.5 \mathrm{~ms}^{-1}$ (Figure $5 a)$, the highest value of total forces $(56.9 \mathrm{kN})$, converted to a plane perpendicular to the rail occurred when both of the heaviest locomotive bogies, marked as $\mathrm{w}_{2}$ and $\mathrm{w}_{3}$, were on rails adjacent to sling Z3 (Figure 2a, Table 3).

The mean for all the results marked with a rectangle in Figs. 5-7, corresponding to the projection of force in the direction perpendicular to the route when the entire locomotive was located on the rails of the measurement section, equalled $51.8 \mathrm{kN}$ and the standard deviation was $2.5 \mathrm{kN}$. Upon comparing these values with the sum of the static projections of the sling reactions of $47.2 \mathrm{kN}$, it ought to be concluded that the average dynamic effect of the route load is greater by $(51.8 / 47.2) \cdot 100 \%=109.7 \%$, with a standard deviation of $5.3 \%$, than the expected static load.

The maximum values of the sum of force projections measured equalled: 56.9, 57.5, 55.4, 54.9, $57.7,57.5$ and were presented in Figures 5-7 respectively. This test was of a normal distribution with a mean of $56.7 \mathrm{kN}$ and a standard deviation of $1.2 \mathrm{kN}$. This means that the maximum dynamic load of the route, considered in the plane perpendicular to it, equalled $120.1 \pm 2.5 \%$ of the static load. On the other hand, the low value of standard deviation $(2.5 \%)$ proves the lack of influence of travel speed, up to $2.0 \mathrm{~ms}^{-1}$, on the maximum values of the force loading the route, as well as high repeatability of the performed tests. It was also pointed out that if the obtained values of the dynamic effect were extrapolated - for trolleys with higher unit weight - such loading could cause reduction of the safety coefficient of the route construction elements to the value $(4.0 / 1.2)=3.3$. The actual value of this coefficient would be even lower if the sling was mounted at the angle $\alpha>0$ measured from the normal plane to the direction of the route.

The results of the Bartlett test, for the range $\mathrm{w}_{1} \mathrm{Z} 1-\mathrm{w}_{6} \mathrm{Z} 8$ marked with a rectangle in Figs. 5-7, are shown in Table 4. It can be observed that the variance (or standard deviation), for the test conducted when the locomotive travels on the incline at a speed of $0.5 \mathrm{~ms}^{-1}$ (standard deviation equal to $3.1 \mathrm{kN}$ in Figure 5b) differs significantly from those obtained for higher speeds. For all the other crossings, regardless of direction, this test showed a statistical equality of standard deviation that ranged from $1.58 \mathrm{kN}$ to $2.51 \mathrm{kN}$. Should one disregard the data presented for the locomotive run at $0.5 \mathrm{~ms}^{-1}$ after elevation (Figure $5 \mathrm{~b}$ ), the recorded total runs (marked $\Sigma$ in the legend) were characterized by homogeneity of variance, i.e., they were statistically similar.

Testing of the means in the studied groups of results, for the range of locomotive positions $\mathrm{w}_{1} \mathrm{Z} 1$ $-\mathrm{w}_{6} Z 8$, was performed using Student's t test. Hypothesis $\mathrm{H}_{0}$ was as follows: the mean values measured for the different groups are not similar to each other. Testing of this hypothesis was done in pairs and with the results in Table 4 indicating equality (or lack thereof) of variance for the different

Table 4. Bartlett results of homogeneity test of variance $\mathrm{H}_{0}$ : for the assumed significance level of 0.05 variances are considered equal for the range $\mathrm{w}_{1} \mathrm{Z1}-\mathrm{w}_{6} \mathrm{Z} 8$

\begin{tabular}{|c|c|c|c|c|c|c|c|c|}
\hline \multirow{3}{*}{$\begin{array}{c}\text { Speed and } \\
\text { direction, } \mathrm{ms}^{-1}\end{array}$} & \multirow{3}{*}{ Figure number } & \multirow{3}{*}{ Test size, - } & \multicolumn{6}{|c|}{ Figure } \\
\hline & & & $5 a$ & $5 b$ & $6 a$ & $6 b$ & $7 a$ & $7 \mathrm{~b}$ \\
\hline & & & \multicolumn{6}{|c|}{ Hipothesis $\mathrm{H}_{0}$ is (a)ccepted/ (r)ejected } \\
\hline $0.5 \mathrm{~d}^{*}$ & $5 a$ & 160 & & $\mathrm{a}$ & a & a & a & a \\
\hline $0.5 \mathrm{i}^{*+}$ & $5 b$ & 149 & a & & $r$ & r & $\mathrm{r}$ & $r$ \\
\hline $1.0 \mathrm{~d}$ & $6 a$ & 81 & a & r & & a & a & a \\
\hline $1.0 \mathrm{i}$ & $6 b$ & 88 & $a$ & $r$ & a & & a & a \\
\hline $2.0 \mathrm{~d}$ & $7 a$ & 37 & $a$ & $r$ & a & $a$ & & a \\
\hline $2.0 \mathrm{i}$ & $7 b$ & 40 & $a$ & $r$ & a & $a$ & a & \\
\hline
\end{tabular}

$\mathrm{d}^{*}-$ decline; $\mathrm{i}^{* *}-$ incline 
Table 5. The results of the t-test of significance of median difference with $\mathrm{H}_{0}$ : for the assumed significance level 0.05 variances are considered equal for the range $\mathrm{w}_{1} \mathrm{Z} 1-\mathrm{w}_{6} \mathrm{Z} 8$

\begin{tabular}{|c|c|c|c|c|c|c|c|c|}
\hline \multirow{3}{*}{$\begin{array}{c}\text { Speed and } \\
\text { direction, } \mathrm{ms}^{-1}\end{array}$} & \multirow{3}{*}{ Figure number } & \multirow{3}{*}{$\begin{array}{c}\text { Test size, } \\
-\end{array}$} & \multicolumn{6}{|c|}{ Figure number } \\
\hline & & & $5 a$ & $5 b$ & $6 a$ & $6 b$ & $7 a$ & $7 \mathrm{~b}$ \\
\hline & & & \multicolumn{6}{|c|}{ Hypothesis $\mathrm{H}_{0}$ is (a)ccepted / (r)ejected } \\
\hline $0.5 \mathrm{~d}^{*}$ & $5 a$ & 160 & & $\mathrm{r}$ & a & $\mathrm{a}$ & a & $\mathrm{r}$ \\
\hline $0.5 \mathrm{i}^{* *}$ & $5 b$ & 149 & r & & $r$ & $r$ & $r$ & $\mathrm{r}$ \\
\hline $1.0 \mathrm{~d}$ & $6 a$ & 81 & $a$ & $\mathrm{r}$ & & a & $\mathrm{a}$ & a \\
\hline $1.0 \mathrm{i}$ & $6 b$ & 88 & $\mathrm{a}$ & $\mathrm{r}$ & a & & a & a \\
\hline $2.0 \mathrm{~d}$ & $7 a$ & 37 & $\mathrm{a}$ & $r$ & $\mathrm{a}$ & $\mathrm{a}$ & & $\mathrm{a}$ \\
\hline $2.0 \mathrm{i}$ & $7 b$ & 40 & $r$ & $r$ & $a$ & $a$ & $a$ & \\
\hline
\end{tabular}

$\mathrm{d}^{*}-$ decline; $\mathrm{i}^{* *}-$ incline

groups. The results of the T-test are presented in Table 5. It can be concluded that the mean sling load is more homogeneous for the passage with higher speed, in particular higher than $0.5 \mathrm{~ms}^{-1}$.

\section{Only the locomotive and the heaviest bogies $w_{3} Z 1-w_{2} Z 8$ are located on the measurement section}

A Kruskal-Wallis test was performed in order to assess the differences in the distribution of the variable for all speed cases examined. For 1083 values belonging to 6 groups of independent data, at a significance level of $\alpha=0.05$ the critical area ranges $(11.07, \infty)$. The value of Kruskal-Wallis Tstatistic was 19.371, therefore the hypothesis had to be rejected. The probability of error through this rejection did not exceed $0.165 \%$. The distribution was tested using the nonparametric Smirnov test. Hypothesis $\mathrm{H}_{0}$ assuming equality of the distribution in paired comparison groups was presented. The results of the statistical analysis for the assumed significance level $\alpha=0.05$ and critical area $(1.358, \infty)$, are presented in Table 6 . It can be observed that the distribution of the data for the $0.5 \mathrm{~ms}^{-1}$ incline run (Figure $5 \mathrm{~b}$ ) is not statistically largely different only from the distribution describing the $2.0 \mathrm{~ms}^{-1}$ incline run (Figure $7 \mathrm{~b}$ ). Furthermore, the distribution for this last travel differed only when compared with the travel at 0.5 $\mathrm{ms}^{-1}$ on the decline presented in Figure 5a.

Based on the evidence presented, it can be concluded that even if the path load analysis were conducted during the ravel with only the heaviest bogies are on the measurement section, there would still be a $67 \%$ probability that the forces measured in the slings are homogenous. In the case described in Table 6 , for 15 pairs of results compared, 10 were statistically identical. Additionally, the description of the decision to accept/ reject the $\mathrm{H}_{0}$ hypothesis in Table 6 differs from Table 5 only for the pair formed by the data for the incline travel at the speeds of $0.5 \mathrm{~ms}^{-1}$ (Figure $5 b$ ) and $2.0 \mathrm{~ms}^{-1}$ (Figure $7 \mathrm{~b}$ ).

\section{Analysis of forces in pairs and separately}

Upon comparing graphs $\mathrm{a}$ and $\mathrm{b}$ in Figure $5-7$, it can be noted that during both travels in opposite directions, significantly lower maximum forces occurred in slings Z4 - Z6 (force sensors D-F), and the least significant forces occurred

Table 6. Results of the Smirnov test for the measurement range $\mathrm{w}_{3} \mathrm{Z1}-\mathrm{w}_{2} \mathrm{Z} 8$

\begin{tabular}{|c|c|c|c|c|c|c|c|c|}
\hline \multirow{3}{*}{$\begin{array}{c}\text { Speed and } \\
\text { direction, } \mathrm{ms}^{-1}\end{array}$} & \multirow{3}{*}{ Figure number } & \multirow{3}{*}{ Test size, - } & \multicolumn{6}{|c|}{ Figure number } \\
\hline & & & $5 a$ & $5 b$ & $6 a$ & $6 b$ & $7 a$ & $7 \mathrm{~b}$ \\
\hline & & & \multicolumn{6}{|c|}{ Hypothesis $\mathrm{H}_{0}$ is (a)ccepted / (r)ejected } \\
\hline $0.5 \mathrm{~d}^{*}$ & $5 a$ & 303 & & $r$ & a & a & a & $r$ \\
\hline $0.5 \mathrm{i}^{* *}$ & $5 b$ & 297 & $\mathrm{r}$ & & $\mathrm{r}$ & $\mathrm{r}$ & $r$ & a \\
\hline $1.0 \mathrm{~d}$ & $6 a$ & 157 & a & $r$ & & a & a & a \\
\hline $1.0 \mathrm{i}$ & $6 b$ & 166 & a & $r$ & a & & a & a \\
\hline $2.0 \mathrm{~d}$ & $7 a$ & 75 & a & $r$ & a & a & & a \\
\hline $2.0 \mathrm{i}$ & $7 \mathrm{~b}$ & 85 & $r$ & a & $a$ & $a$ & $a$ & \\
\hline
\end{tabular}

$\mathrm{d}^{*}$ - decline; $\mathrm{i}^{* *}-$ incline 
in slings Z6 (F). An explanation for this fact is possible based on the geometry of the route. The lengths of the rails, located between the mentioned slings, were smaller in comparison to the lengths of the rails of the rest of the measurement route, as presented in Table 1.

A comparison of the maximum forces recorded by the sensors while the locomotive was travelling in different directions is concluded in Table 7. The value of the force measured by individual sensors during the incline travel differed by more than $13 \%$, compared to the force occurring in the same sling during the decline travel at the speed of $0.5 \mathrm{~ms}^{-1}$. Such a dependency occurred for the force sensor E, mounted on the sling Z5. It is to be noted that during this travel, for the slings adjacent to sling Z5, the result of such a comparison was the opposite, mainly less than 1. Sensors F and D (Z6 and Z4) recorded greater maximum forces during the tractor run on the downhill than on the uphill, and these differences were $9.5 \%$ and $5.0 \%$, respectively. In the case of sling Z1, a maximum force was observed to be almost $7.0 \%$ greater during the downward travel than during the upward travel at the same speed. For the four sensors, designated $\mathrm{B}, \mathrm{F}$ and $\mathrm{G}-$ installed on slings $\mathrm{Z} 2, \mathrm{Z3}, \mathrm{Z7}$ and $\mathrm{Z} 8$ - the mentioned difference was less than $5.0 \%$ of the value.
The greatest differences, a quotient of 1.167 and 0.864 (Table 7), were noticed between the forces generated in slings Z1 and Z6 (sensors F and A) when passing in different directions at the speed of $2.0 \mathrm{~ms}^{-1}$. However, the opposite case was usually recorded in slings Z2 and Z7, which were next to the one for which these significant differences occurred. As a result, the average change in the value of forces in all slings jointly, for the same speed of passage of the queue, did not differ by more than $1.3 \%$ and occurred at a speed of 2.0 $\mathrm{ms}^{-1}$. This means that - taking into account the entire section of the measurement - local differences in the load between individual slings may be found, but a higher load on one of the slings is associated with a corresponding decrease in the load of other slings, most often those located near the first one.

Figure 8 presents statistics for the mean quotients (from Table 7) of the maximum forces obtained in all slings during incline and decline travels. It can be observed that the quotient was of a higher value in the case the speed of the run was higher, but these differences were deemed insignificant. The greatest range of variation in the results was determined for the travels at $2 \mathrm{~ms}^{-1}$. However, considering the average dependency (Mean series in Table 7 and Figure 8) when running at different speeds, all the results

Table 7. Comparison of maximum forces registered by sensors during the travel on decline and incline

\begin{tabular}{|c|c|c|c|c|c|c|c|c|}
\hline \multirow{4}{*}{$\begin{array}{c}\text { Speed and } \\
\text { direction, } \mathrm{ms}^{-1}\end{array}$} & \multicolumn{8}{|c|}{ Sling designation } \\
\hline & Z1 & Z2 & Z3 & Z4 & Z5 & Z6 & $\mathrm{Z7}$ & Z8 \\
\hline & \multicolumn{8}{|c|}{ Designation of the force sensor } \\
\hline & A & B & C & D & $E$ & $\mathrm{~F}$ & G & $\mathrm{H}$ \\
\hline 0.5 & \multicolumn{8}{|c|}{ Force value, $\mathrm{kN}$} \\
\hline Incline & 26.01 & 23.53 & 26.30 & 20,67 & 18.39 & 21.28 & 24.40 & 25.38 \\
\hline \multirow[t]{2}{*}{ Decline } & 27.88 & 22.82 & 25.89 & 21.75 & 16.23 & 23.51 & 25.50 & 25.40 \\
\hline & \multicolumn{8}{|c|}{ Relative change, - } \\
\hline Incline / Decline & 0.933 & 1.031 & 1.016 & 0.950 & 1.133 & 0.905 & 0.957 & 0.999 \\
\hline 1.0 & \multicolumn{8}{|c|}{ Force value, kN } \\
\hline Incline & 28.04 & 22.77 & 25.95 & 20.35 & 15.88 & 21.12 & 24.18 & 25.24 \\
\hline \multirow{2}{*}{ Decline } & 28.53 & 22.18 & 25.08 & 20.27 & 16.22 & 19.93 & 24.74 & 25.94 \\
\hline & \multicolumn{8}{|c|}{ Relative change, - } \\
\hline Incline / Decline & 0.983 & 1.027 & 1.035 & 1.004 & 0.979 & 1.058 & 0.977 & 0.973 \\
\hline 2.0 & \multicolumn{8}{|c|}{ Force value, $\mathrm{kN}$} \\
\hline Incline & 24.09 & 23.46 & 26.36 & 20.73 & 18.76 & 23.09 & 23.80 & 25.44 \\
\hline \multirow[t]{2}{*}{ Decline } & 27.88 & 21.87 & 25.52 & 20.69 & 19.24 & 19.78 & 24.69 & 24.79 \\
\hline & \multicolumn{8}{|c|}{ Relative change, - } \\
\hline Incline / Decline & 0.864 & 1.073 & 1.033 & 1.002 & 0.975 & 1.167 & 0.964 & 1.026 \\
\hline Mean & 0.960 & 1.044 & 1.028 & 0.985 & 1.029 & 1.043 & 0.966 & 0.999 \\
\hline
\end{tabular}




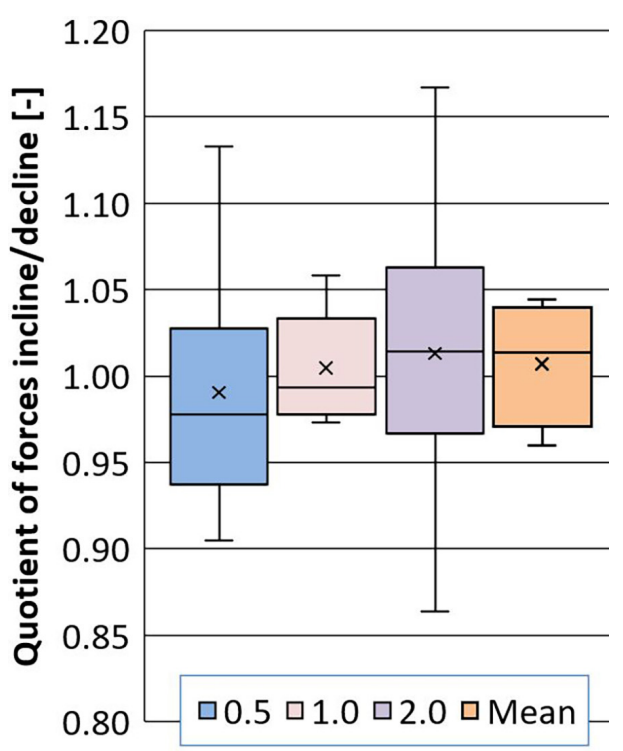

Fig. 8. Comparison of the mean force quotients across all slings combined when driven at different speeds and the mean in the last row of Table 7

are oscillating in the range of the value of 1.0, which confirms the lack of influence of the direction of the run on the values of the forces in the slings. During the downward travel, the forces in the slings were greater than during the upward travel (quotient $<1.0$ ) only when the tractor was driven at $0.5 \mathrm{~ms}^{-1}$, but this difference was minimal as it did not exceed $1 \%$ on average. Should the results recorded for all speeds be considered, the mean dependency (Mean series in Table 7 and Figure 8) was slightly $>1.0$. In general, the values of the maximum forces measured during uphill driving were only $0.7 \%$ greater than during downhill driving.

The force values of slings $\mathrm{Z} 2$ and $\mathrm{Z} 8$ and $\mathrm{Z3}$ and $Z 7$ were also compared due to the fact that they are adjacent to the longest rails and the pairs are connected at a similar angle $\alpha$ (Table 1). The maximum force values, examined separately for each sling present a normal distribution. For the $\mathrm{Z} 3$ pair, with a mean of $25.85 \mathrm{kN}$, and $\mathrm{Z7}$, with a mean of $24.55 \mathrm{kN}$, the maximum forces measured in the slings ranged from 23.80 to $26.36 \mathrm{kN}$ and the means differed by $1.30 \mathrm{kN}$ only. In addition, upon taking into account the small difference in standard deviation, which were $0.48 \mathrm{kN}$ and 0.58 $\mathrm{kN}$, these results can be evaluated as having high convergence (equality of variance). The obvious conclusion from these considerations is that if the slings are characterized by the same geometrical parameters (as shown in Table 1), then their loading is the same.
Although the sling pair Z2, with an average of $22.77 \mathrm{kN}$, and $\mathrm{Z8}$, with an average of 25.37 $\mathrm{kN}$, was also characterized by a similar angle $\alpha$, the difference in the measured force values was very significant. The force values ranged from 21.9 to $26.0 \mathrm{kN}$, and the standard deviation was twice as large as for slings Z3 and Z7. This difference can be explained by the fact that the $L_{Z}$ length of sling $Z 2$ was $90 \mathrm{~mm}$ greater than that of sling Z8 (Table 1), therefore. not all geometric parameters were identical. It ought to be concluded that characterizing the sling by angle alone does not prove sufficient. The sling $\mathrm{Z} 8$, shorter than the compared sling Z2, was installed in the unloaded state at a slightly larger angle $\alpha$ and was also exposed to larger changes in this angle after the route was loaded during the locomotive travel.

On the basis of the data in Table 7 and Figure 8 , an important conclusion can be drawn that the average force values in the slings were not dependent on the direction of the tractor travel. Since the maximum forces in the sensors with which the slings were equipped proved similar when the locomotive travelled on the decline and on the incline, it is sufficient to perform tests only when the locomotive travels in one direction. A practical conclusion from these tests is that the number of runs necessary to take the measurements can be reduced because the maximum force values in each sling are comparable in each direction of travel.

Table 8 shows the comparison of the maximum forces recorded by the individual sensors with the forces calculated from the static load. The static load of the sling was calculated on the basis of equation (3) as caused by the weight of the heaviest bogies of the overhead railroad tractor when they are located on the rails of this sling. The greatest dynamic load on a single sling was observed when one of the heaviest bogies, $\mathrm{w}_{2}$ or $\mathrm{w}_{3}$ (Table 2), was located exactly where this sling was mounted to the rail joint (Table 3 ).

The lowest value of the static force was obtained using formula (3) for the sling Z5 (Table 8) placed between the shortest rails on the measured route (Figure 2, Table 1). The force values calculated for the remaining slings differ by a maximum of $9.3 \%$. Including the Z5 sling, the difference exceeded $30 \%$, therefore it can be assumed that similar relations ought to be expected between the measured force values for the most loaded sling placed on the measured route. 
Table 8. Characteristics of static forces in slings, calculated from Eq. (3), maximum forces measured at different speeds and quotient between measured and calculated

\begin{tabular}{|c|c|c|c|c|c|c|c|c|}
\hline Sling designation & $\mathrm{Z1}$ & $\mathrm{Z2}$ & $\mathrm{Z3}$ & Z4 & $\mathrm{Z5}$ & Z6 & $\mathrm{Z7}$ & Z8 \\
\hline Force sensor & A & B & C & $\mathrm{D}$ & $\mathrm{E}$ & $\mathrm{F}$ & G & $\mathrm{H}$ \\
\hline \multirow[t]{2}{*}{ Calculated force, $\mathrm{kN}$} & 23.57 & 23.88 & 23.74 & 22.14 & 18.35 & 21.86 & 23.74 & 23.89 \\
\hline & \multicolumn{8}{|c|}{ The highest value of force at $0.5 \mathrm{~ms}^{-1}$} \\
\hline (D)ecline | (I)ncline & d & $\mathrm{i}$ & $\mathrm{i}$ & $d$ & $\mathrm{i}$ & d & d & d \\
\hline Measured force, $\mathrm{kN}$ & 27.88 & 23.53 & 26.30 & 21.75 & 18.39 & 23.51 & 25.50 & 25.40 \\
\hline \multirow[t]{2}{*}{ Measured / Calculated } & 1.183 & 0.985 & 1.108 & 0.982 & 1.002 & 1.075 & 1.074 & 1.063 \\
\hline & \multicolumn{8}{|c|}{ The highest value of force at $1.0 \mathrm{~ms}^{-1}$} \\
\hline (D)ecline | (I)ncline & d & $\mathrm{i}$ & $\mathrm{i}$ & $\mathrm{i}$ & $d$ & $\mathrm{i}$ & d & d \\
\hline Measured force, $\mathrm{kN}$ & 28.53 & 22.77 & 25.95 & 20.35 & 16.22 & 21.12 & 24.74 & 25.94 \\
\hline \multirow[t]{2}{*}{ Measured / Calculated } & 1.210 & 0.954 & 1.093 & 0.919 & 0.884 & 0.966 & 1.042 & 1.086 \\
\hline & \multicolumn{8}{|c|}{ The highest value of force at $2.0 \mathrm{~ms}^{-1}$} \\
\hline (D)ecline | (I)ncline & $d$ & $\mathrm{i}$ & $\mathrm{i}$ & $\mathrm{i}$ & $d$ & $\mathrm{i}$ & $d$ & $\mathrm{i}$ \\
\hline Measured force, $\mathrm{kN}$ & 27.88 & 23.46 & 26.36 & 20.73 & 19.24 & 23.09 & 24.69 & 25.44 \\
\hline Measured / Calculated & 1.183 & 0.982 & 1.110 & 0.936 & 1.049 & 1.056 & 1.040 & 1.065 \\
\hline
\end{tabular}

The obtained measurements, presented in Table 8 , were usually greater than those calculated from formula (1), but their quotient ranged from 0.884 to 1.210 . The occurrence of a value of this quotient smaller than 1 means that the estimation of the highest value of the sling load force based on force measurements in only one sling may be burdened with a large error.

The largest differences between the measured and calculated values were recorded for sling Z1 with the sensor A. On average, when the locomotive passed at any speed, the force recorded by this sensor was more than $19 \%$ greater than the calculated force. The smallest quotient (0.884) occurred for sling Z5, on which the force sensor marked E was installed; however, this dependency occurred only when the locomotive passed at a speed of $1.0 \mathrm{~ms}^{-1}$. At each travelling speed, a smaller force was recorded for slings $Z 1$ and Z4 than the force calculated from equation (1). However, while for the first sling the quotient of the values averaged 0.973 , for the second one it reached 0.945 . Comparing the average quotients of the measured forces to the calculated ones for all slings for a given travel speed, values differing by no more than $6 \%$ were obtained.

To summarize, upon considering all crossings, the forces measured in the sling sensors were $4.4 \%$ greater than the forces calculated for the static load. The railroad, along an inclined suspension route, may cause an increase in the force value, compared to the calculated one, up to $21 \%$ for a single sling installed at an angle $\alpha$ of up to about $15^{\circ}$.

\section{CONCLUSIONS}

In this paper, it is shown that the values of forces measured in the slings the for the moving transport set can significantly differ from those derived from the static model. Although the dynamic forces generated during braking of the set are greatly more significant than the forces measured during driving, according to the literature reports $[11,12,14]$, the authors of these publications do not calculate the force values during the passage of the suspended train at a constant speed.

Upon considering the fact that according to equations (1) and (2) the sling load depends on the function $\sec (\alpha)$, the predicted change in the value of the angle $\alpha$ as a result of the route loading can lead to an increase of maximum $0.9 \%$ in the sling force load.

The above presented results confirmed the hypothesis presented by the authors in an earlier publication stating that in order to analyse the values of forces in slings, it is necessary to project them onto a plane perpendicular to the route to eliminate the effect of the angle of the sling, which, as shown in this work, can vary by several degrees even in the case of adjacent single leg slings. An additional projection enables one to analyse the total load of the route slings by the entire transport set. Such an action is advisable, since it increases research quality and the statistical reliability of results, It is possible especially when the measured section of the suspended route has a length greater than the length of the set used for testing. An analysis of the test results so processed in this paper leads to the 
conclusion that the maximum load on the route in the plane perpendicular to it equals $120.1 \pm 2.5 \%$ of the static load. Despite the fact that this analysis was performed for locomotive travelling at three speeds from $0.5 \mathrm{~ms}^{-1}$ to $2.0 \mathrm{~ms}^{-1}$ and in different directions, the standard deviation of $2.5 \%$ is insignificant and shows a high repeatability of the tests.

In addition, it was stated that even if the analysis of the route load was conducted during the travel when only the heaviest trolleys are located on the measured section, there is still a $67 \%$ probability that the total route load at different travel speeds will be identical.

It was also shown that the dynamic load on the part of the route slightly above the current locomotive position occurs both in the downhill and uphill direction for all given travel speeds. The value of the total load on all slings of this part of the route was equal to the weight of the heaviest locomotive bogies. During downhill travel, the total reaction forces of the route's slings "remember" the heaviest load, and during uphill travel, they "anticipate" the arrival of the heaviest bogies.

The greatest variation in the values of the total forces observed in the slings, related to the direction normal to the route, occurred in that part of the route with the shortest rails, mainly slings Z5 and Z6 with force sensors E and F, and for passing speeds of $1.0 \mathrm{~ms}^{-1}$ and $2.0 \mathrm{~ms}^{-1}-$ also slings Z4 with sensor D.

In the case of a single sling placed at an angle of up to about $15^{\circ}$, the travel of a locomotive, regardless of speed and direction, along a route inclined at an angle of about $10^{\circ}$ increased force by as much as $21 \%$ compared to the value calculated for static load. This value is similar to the determined, for the whole dynamic effect in the normal plane locomotive and the whole route, i.e. $120.1 \pm 2.5 \%$.

In general, it can be stated that increasing the travel speed causes a "smoothing" of the force courses and an increase in the probability that the force values in the slings are more similar in terms of the distribution - for data with a distribution other than normal - or the mean value (maximum) and variance (standard deviation).

Further research will be carried out to determine the maximum load on the elements of the suspended monorail route during a controlled change in the speed of the train and braking, as well as upon increasing mass per bogie. The aim of this research is to develop a coherent mathematical model of the suspended monorail and track dynamics.

\section{Acknowledgements}

The project/research was financed in the framework of the project Lublin University of Technology-Regional Excellence Initiative, funded by the Polish Ministry of Science and Higher Education (contract no. 030/RID/2018/19).

\section{REFERENCES}

1. Gao F., Xiao L.J., Ma H.G., Guo S. Analysis on the Construction of the Monorail Hoist Auxiliary Transportation System in Coal Mine. Applied Mechanics and Materials. 2013; 278-280: 189-192.

2. Beker Mining Systems AG. Minetrans, from https:/www.becker-mining.com/sites/default/files /BM-GER-TRANSPORT_web.pdf, accessed on 2021-08-27.

3. Famur Group. Diesel Locomotive FMS, https:// famur.com/en/diesel-locomotive-fms, accessed on 2021-08-27.

4. Drozd K., Nieoczym A. Dynamic load of suspension chains generated during the movement of the selfpowered diesel transportation system on a suspended monorail track in the mining excavation (in Polish). Lublin University of Technology Edition; 2020.

5. Cvijović G.M., Bošnjak S.M. Calculation methods' comparative analysis of monorail hoist crane local bending effects. Tehnika. 2016; 71(4): 563-570.

6. DIN 22252:2012. Round steel link chains for use in continuous conveyors and winning equipment in mining. Deutsches Institut für Normung. Berlin.

7. PN-G-46701:1997. Łańcuchy ogniwowe górnicze. Polski Komitet Normalizacyjny. Warszawa.

8. ISO 610:1990. High-tensile steel chains (round link) for chain conveyors and coal ploughs. International Organization for Standardization-ISO/TC 82 Mining. Geneva.

9. Tokarczyk J., Rotkegel M., Pytlik A., Niedworok A. Research on the impact of forces and acceleration during the riding and braking of a suspended monorail. Archives of Mining Sciences. 2020; 65(2): 399-414.

10. Gutarevich V.O., Kondratenko M.P. Dynamics of traction device of mine suspended monorail road. Sustainable Development of Mountain Territories. 2020; 12(3): 410-417.

11. Gutarevich V.O. Longitudinal dynamics of mine suspended monorail. Naukovyi Visnyk Natsionalnoho Hirnychoho Universytetu. 2015; 5(1): 83-88.

12. Pytlik A. Tests of steel arch and rock bolt support resistance to static and dynamic loading induced by suspended monorail transportation. Studia Geotechnica et Mechanica. 2019; 41(2): 81-92. 
13. Horyl P., Šn̆upárek R., Maršálek P., Poruba Z., Pacześniowski K. Parametric Studies of Total Load-Bearing Capacity of Steel Arch Supports. Acta Montanistica Slovaca. 2019; 24(3): 213-222.

14. Tokarczyk J. Method for identification of results of dynamic overloads in assessment of safety use of the mine auxiliary transportation system. Archives of Mining Sciences. 2016; 61(4): 765-777.

15. Szewerda K., Tokarczyk J., Pytlik A. Suspended monorail emergency braking trolley computational model verification based on bench tests. IOP Conference Series: Earth and Environmental Science. 2019; 261: 012052.

16. Tokarczyk J., Dudek M. Methods for computer aiding the configuration and assessment of auxiliary mine transportation means. Management Systems in Production Engineering. 2020; 28(4): 268-275.
17. Herbuś K., Szewerda K., Świder J. Virtual prototyping of the suspended monorail in the aspect of increasing the permissible travel speed in hard coal mines. Eksploatacja i Niezawodność - Maintenance and Reliability. 2020; 22(4): 610-619.

18. Prochowski L., Żuchowski A. Analysis of the influence of passenger position in a car on a risk of injuries during a car accident. Eksploatacja i Niezawodność Maintenance and Reliability. 2014; 16(3): 360-366.

19. Axis Sp. z o.o. Meters with external sensor, from https://www.axis.pl/en/pk-meters-with-externalsensor-133.html, accessed on 2021-08-27.

20. Famur Group. Suspended Monorail Tracks, from http://famur.com/en/suspended-monorail-tracks, accessed on 2021-08-27.

21. Ferrit - Global Mining Solutions, Důlní závěsná lokomotiva, from http://www.ferrit.cz/cs/produkty/ zavesna-doprava/lokomotivy-dieselove/dlz110f-ii, accessed on 2021-08-27. 